\title{
Copper Bottom-Up Filling by Electroplating Without any Additives on Patterned Wafer
}

\author{
Seung Hwan Cha, ${ }^{\mathrm{a}}$ Seung-Soo Kim, ${ }^{\mathrm{b}}$ Sung Ki Cho, ${ }^{\mathrm{b}}$ and Jae Jeong Kim ${ }^{\mathrm{b}, *, \mathrm{z}}$ \\ ${ }^{a}$ LG Philips LCD Research and Development Center, 533, Hogae-dong, Dongan-gu, Anyang-shi, \\ Gyongki-do 431-080, Korea \\ ${ }^{b}$ Research Center for Energy Conversion and Storage, School of Chemical and Biological Engineering, \\ College of Engineering, Seoul National University, San 56-1, Shillim-dong, Kwanak-gu, Seoul \\ 151-742, Korea
}

In conventional $\mathrm{Cu}$ electroplating, various additives are used to fill pattern without defects in patterned wafers. Pulse plating and electrochemical oxidation were used to deposit $\mathrm{Cu}$ without any additives. Defects such as voids and seams were generated if only pulse plating was carried out. Electrochemical oxidation was performed to remove $\mathrm{Cu}$ metal containing defects and to remain $\mathrm{Cu}$ species only at the bottom part of the trenches. Then, defect free $\mathrm{Cu}$ films could be obtained when $\mathrm{Cu}$ electroplating without additives was performed on the etched substrate.

(C) 2006 The Electrochemical Society. [DOI: 10.1149/1.2400207] All rights reserved.

Manuscript submitted June 11, 2006; revised manuscript received September 18, 2006.

Available electronically December 13, 2006.

Electroplating has been recently developed to form $\mathrm{Cu}$ interconnects in ultralarge scale integrated chips. ${ }^{1}$ It is known that additives such as suppressors and accelerators are required in the electrolyte to perform gap filling in patterned wafers. ${ }^{2}$ In this case, however, it is difficult to control the electroplating process and the incorporation of additives in $\mathrm{Cu}$ films increases their overall resistivity. Hence, it is desirable to plate $\mathrm{Cu}$ layers using an electrolyte without additives.

In our previous paper, ${ }^{3} \mathrm{Cu}$ gap filling using electrochemical oxidation instead of accelerators was accomplished. In those experiments, defect free $\mathrm{Cu}$ films were electroplated after $\mathrm{Cu}$ films which were conformally deposited using suppressor were etched by phosphoric acid. $\mathrm{Cu}$ can be conformally plated by two methods: $\mathrm{Cu}$ electrodeposition using suppressors and $\mathrm{Cu}$ pulse plating. Polyethylene glycol- $\mathrm{Cl}$ and benzotriazole have been used as suppressors in order to plate $\mathrm{Cu}$ layers conformally. ${ }^{3}$ According to Seah, $\mathrm{Cu}$ can be conformally deposited by pulse plating as well. ${ }^{4}$ Therefore, in this experiments, a pulse plating technique was attempted to produce defect free $\mathrm{Cu}$ films in trenches by electroplating without additives.

The structure of trenches used in this study were TiN $(10 \mathrm{~nm}) /$ $\mathrm{Ti}(15 \mathrm{~nm}) / \mathrm{Si}$. The TiN layer was used as a $\mathrm{Cu}$ diffusion barrier. The Ti and TiN layers were deposited by ionized metal plasma physical vapor deposition (PVD) and metallorganic chemical vapor deposition, respectively. The width of the trenches were $0.6 \mathrm{um}$ and the aspect ratio was 1.5:1. A seed layer is necessary to deposit $\mathrm{Cu}$ by electroplating. In this experiment, a $100 \mathrm{~nm}$ thick seed layer was prepared by $\mathrm{Cu}$ PVD. During electroplating, the area of the cathode was set at $1 \mathrm{~cm}^{2}$. The electrolyte used for electroplating was composed of $1 \mathrm{M} \mathrm{H}_{2} \mathrm{SO}_{4}, 0.25 \mathrm{M} \mathrm{CuSO}_{4} \cdot 5 \mathrm{H}_{2} \mathrm{O}$, and deionized water. No additives were present in the electrolyte. An $\mathrm{Au}$ wire and a saturated calomel electrode (SCE) were used as the counter and the reference electrodes, respectively.

To deposit the $\mathrm{Cu}$ layer conformally, pulse plating was performed for $5 \mathrm{~min}$. The current density during on time was controlled at $10 \mathrm{~mA} / \mathrm{cm}^{2}$. When the current density was above $15 \mathrm{~mA} / \mathrm{cm}^{2}, \mathrm{Cu}$ was deposited mainly at the upper part of the trench; deposit was controlled by a mass transfer limited reaction. The on/off frequencies used in these experiments were $50 \mathrm{~Hz}, 250 \mathrm{~Hz}, 1 \mathrm{kHz}$, and $5 \mathrm{kHz}$, and the duty cycle was $50 \%$.

As a result of pulse plating, seams and voids were generated in

\footnotetext{
* Electrochemical Society Active Member.

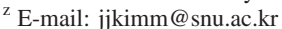

the deposited $\mathrm{Cu}$ layer. To etch the defects in the $\mathrm{Cu}$ film and to remain $\mathrm{Cu}$ metal only at the bottom part of trench, a constant potential of $1.25 \mathrm{~V}$ vs SCE was applied for $15 \mathrm{~s}$ to the substrate in a $85 \% \mathrm{H}_{3} \mathrm{PO}_{4}$ solution, as optimized in our previous paper. ${ }^{3}$ Finally, electroplating was performed on the etched substrate at a constant current of $2 \mathrm{~mA} / \mathrm{cm}^{2}$ to achieve bottom up filling.

First, $\mathrm{Cu}$ was electrodeposited on a $\mathrm{Cu}$ seed layer under a constant current of $10 \mathrm{~mA} / \mathrm{cm}^{2}$ in electrolyte without any additives. $\mathrm{Cu}$ was conformally deposited while $\mathrm{Cu}$ ions existed in a diffusion layer in the initial stage of electroplating. $\mathrm{Cu}$ ions were supplied by diffusion from the bulk phase after all of the $\mathrm{Cu}$ ions in the diffusion layer were deposited, indicating that the deposition rate of $\mathrm{Cu}$ ions is determined by mass transfer. Diffused $\mathrm{Cu}$ ions were reduced at the upper part of trench before the ions were uniformly distributed in the diffusion layer. As a result, voids were generated in the trench, as shown in Fig. 1, because $\mathrm{Cu}$ was mainly deposited at the upper part of the trench without filling the trench with $\mathrm{Cu}$ metal.

Pulse plating on the $\mathrm{Cu}$ seed layer was performed without additives. In pulse plating, uniform $\mathrm{Cu}$ reduction throughout the substrate surface can be generated by $\mathrm{Cu}$ ion diffusion during the off time. $^{5}$ At the frequencies of $50 \mathrm{~Hz}, 250 \mathrm{~Hz}, 1 \mathrm{kHz}$, and $5 \mathrm{kHz}$, a considerable amount of $\mathrm{Cu}$ was deposited in the trench (Fig. 2). The amount of $\mathrm{Cu}$ reduced in the trench increased with an increase in frequency. This was attributed to the increase in mass transfer limited $\mathrm{Cu}$ reduction time during the longer on time at shorter frequencies. However, defects such as voids still existed in

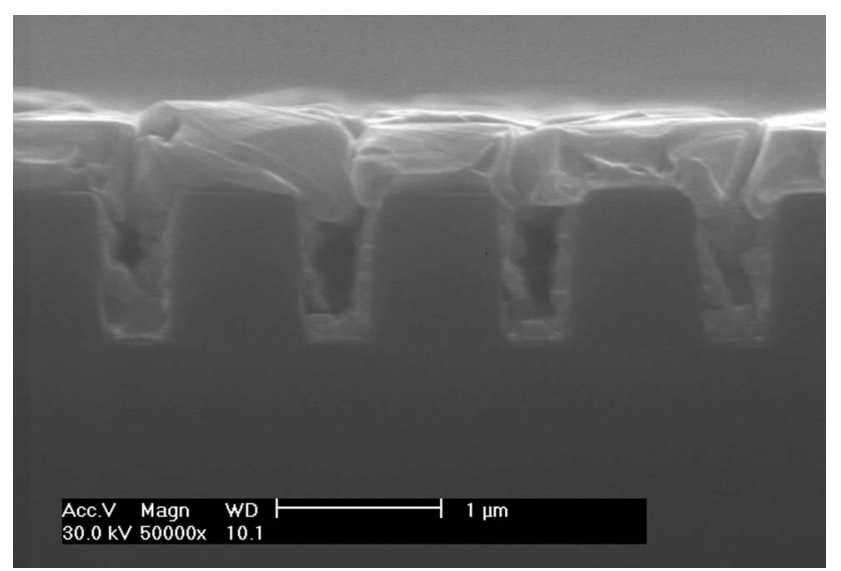

Figure 1. FESEM of electroplated $\mathrm{Cu}$ species without any additives. 


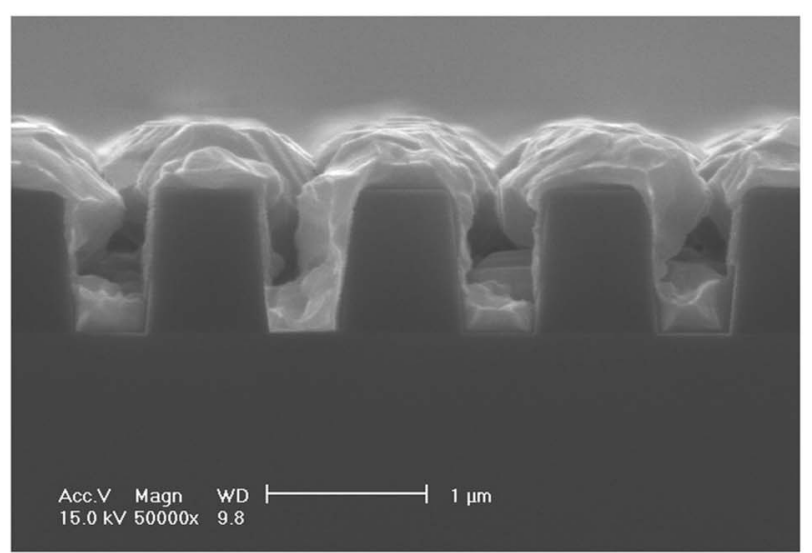

(a)

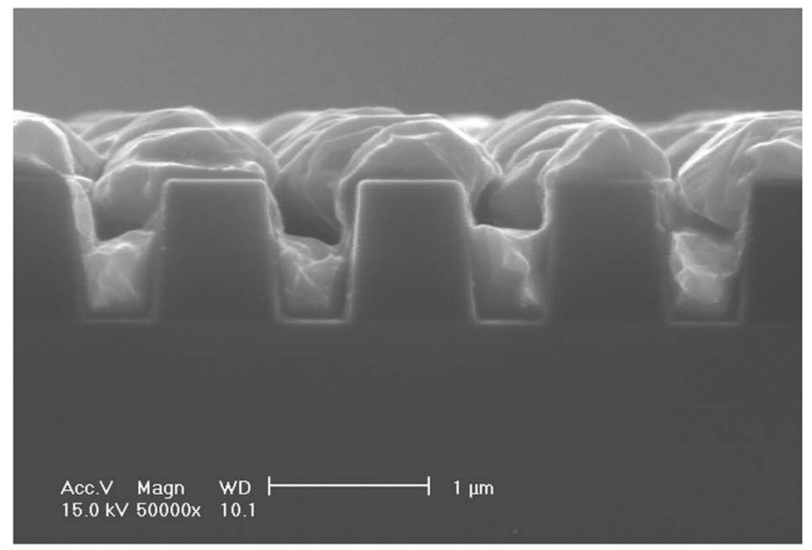

(c)

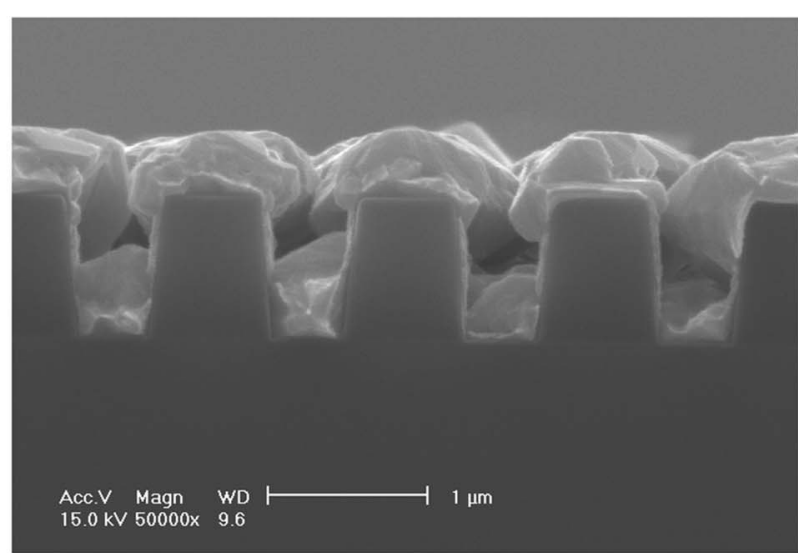

(b)

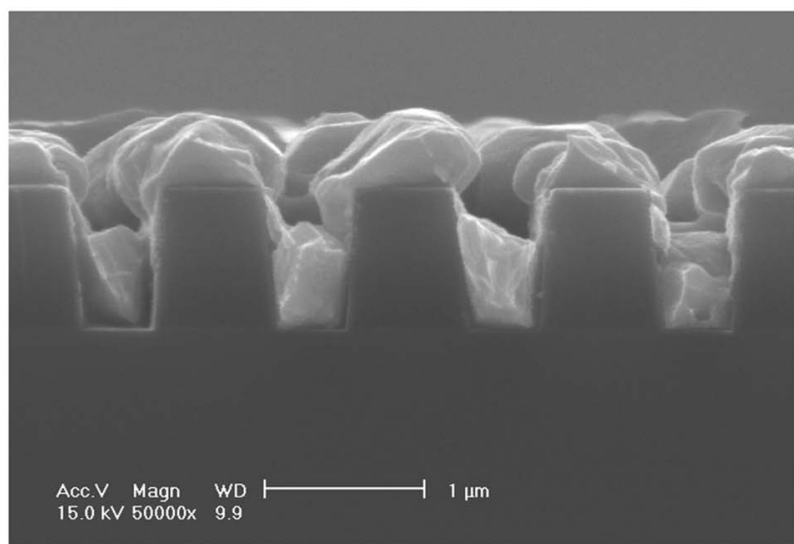

(d)

Figure 2. FESEM of $\mathrm{Cu}$ film which was pulse plated at the frequency of (a) $50 \mathrm{~Hz}$, (b) $250 \mathrm{~Hz}$, (c) $1 \mathrm{kHz}$, and (d) $5 \mathrm{kHz}$.

the trench at allfrequencies. It has been reported that it is impossible to perform $\mathrm{Cu}$ gap filling without defects by using only pulse plating. 4,6

The subsequent $\mathrm{Cu}$ etching process was carried out to remove $\mathrm{Cu}$ metal at the upper part of the trench and $\mathrm{Cu}$ species containing defects in the trench. Because $\mathrm{Cu}$ was etched vertically

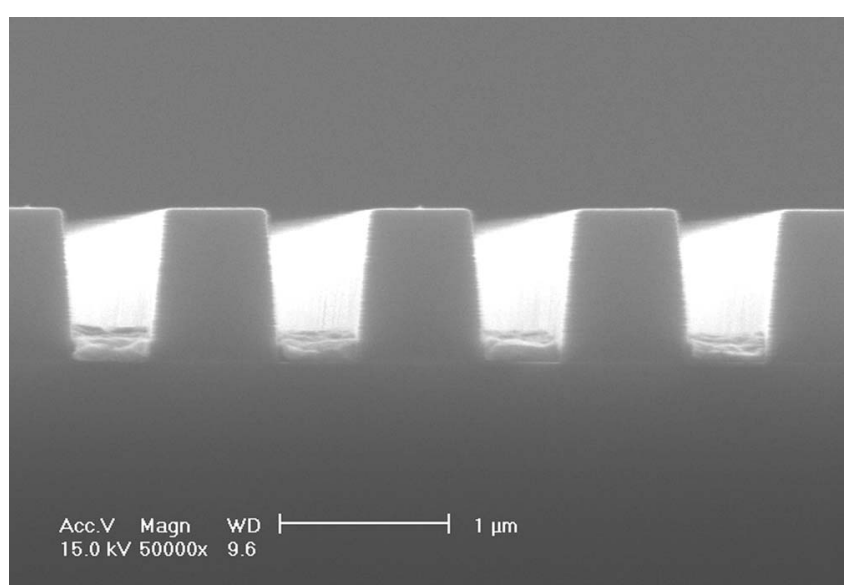

Figure 3. $\mathrm{Cu}$ electrochemical oxidation of $\mathrm{Cu}$ film which was pulse plated at the frequency of $1 \mathrm{kHz}$ in a $\mathrm{H}_{3} \mathrm{PO}_{4}$ solution, ${ }^{3}$ the $\mathrm{Cu}$ film could remain only at the bottom part of the trench after $\mathrm{Cu}$ electrochemical oxidation, as shown in Fig. 3.

In this experiment, $\mathrm{Cu}$ is electrochemically etched by ${ }^{7}$

$$
\begin{gathered}
\mathrm{Cu} \rightarrow \mathrm{Cu}_{\text {ads }}^{2+}+2 \mathrm{e}^{-} \\
6 \mathrm{H}_{2} \mathrm{O}+\mathrm{Cu}_{\mathrm{ads}}^{2+} \rightarrow\left[\mathrm{Cu}\left(\mathrm{H}_{2} \mathrm{O}\right)_{6}\right]^{2+}
\end{gathered}
$$

If $\mathrm{Cu}$ was electrically isolated after the complete $\mathrm{Cu}$ etching a the upper part of trench, $\mathrm{Cu}$ would not be etched any more in $\mathrm{H}_{3} \mathrm{PO}_{4}$ solution. However, $\mathrm{Cu}$ etching kept going so that the proper etching time led to $\mathrm{Cu}$ remaining only at the bottom part of trench since a TiN diffusion barrier played a role of the current path to etch. The TiN diffusion barrier remained even after $\mathrm{Cu}$ electrochemical oxidation and was also used as the current path for the subsequent electroplating process.

Finally, $\mathrm{Cu}$ was electroplated without any additives on the etched substrate. Because $\mathrm{Cu}$ was deposited vertically, ${ }^{3}$ defect free $\mathrm{Cu}$ films could be generated by dc plating at all frequencies (Fig. 4).

\section{Conclusion}

In this study, $\mathrm{Cu}$ electroplating on patterned wafers was performed. To obtain defect free $\mathrm{Cu}$ films, pulse plating and electrochemical oxidation were used in place of additives. By using pulse plating, the amount of $\mathrm{Cu}$ metal reduced in the trench could increase. As a result, the margin of subsequent electrochemical oxida- 


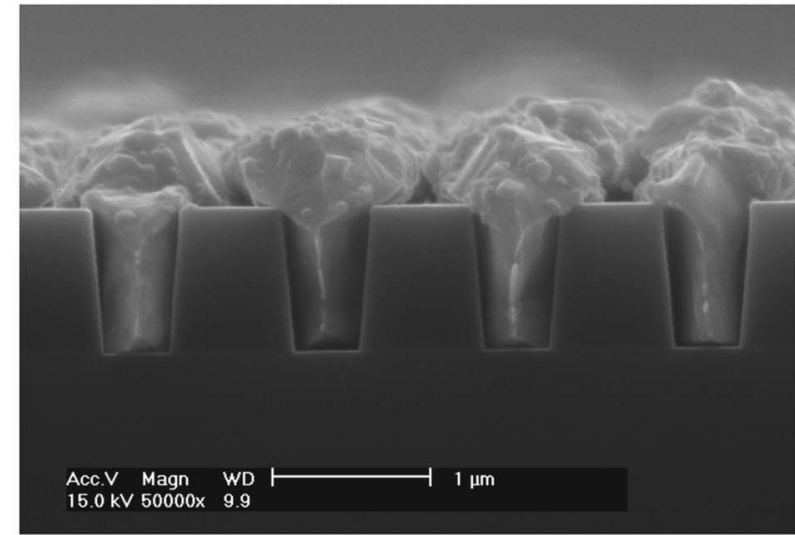

(a)

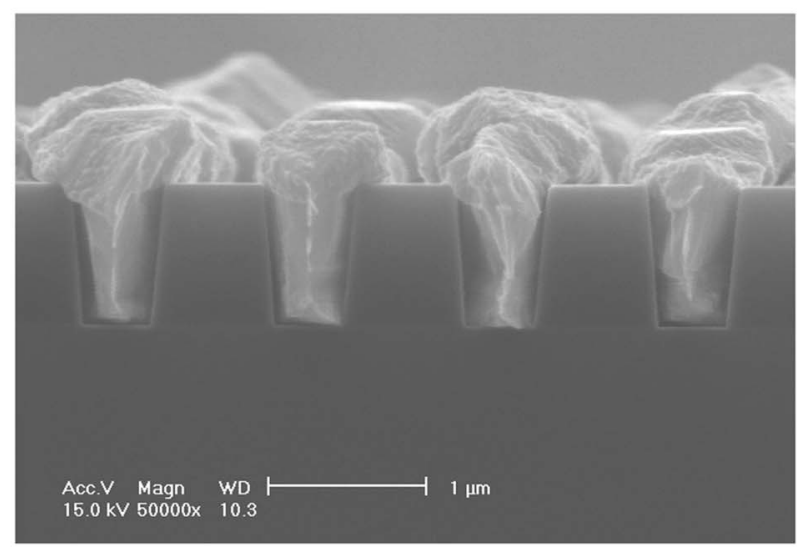

(c)

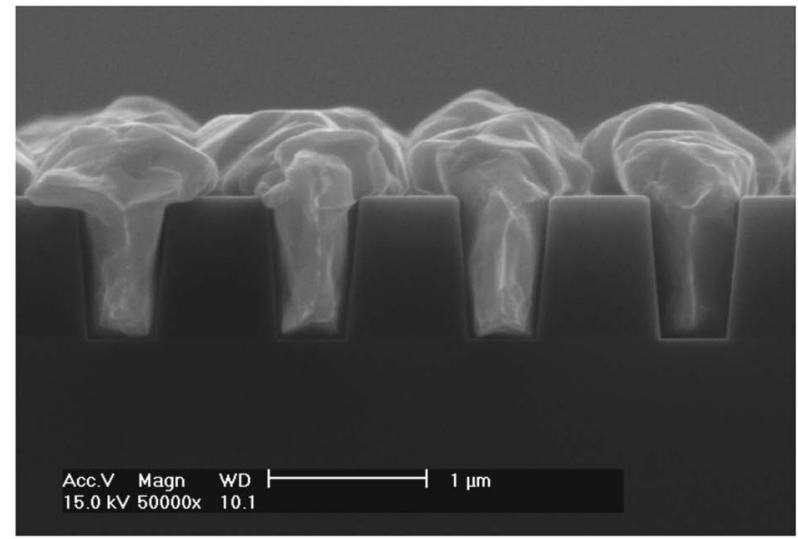

(b)

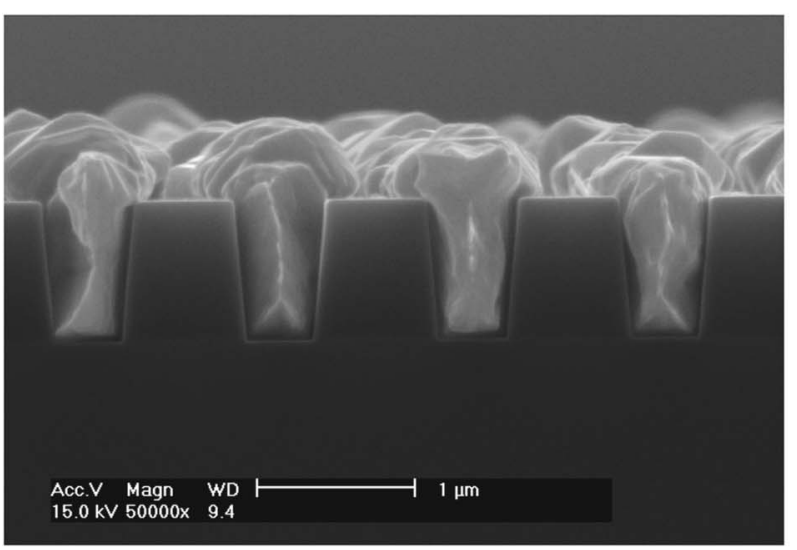

(d)

Figure 4. $\mathrm{Cu}$ dc electroplating after etching substrate which was pulse plated at the frequency of (a) $50 \mathrm{~Hz}$, (b) $250 \mathrm{~Hz},(\mathrm{c}) 1 \mathrm{kHz}$, and (d) $5 \mathrm{kHz}$.

tion of $\mathrm{Cu}$ species in the trench increased. After electrochemical oxidation, defect free $\mathrm{Cu}$ gap filling was achieved by electroplating without any additives.

\section{Acknowledgment}

This work was supported by KOSEF through the Research Center for Energy Conversion and Storage (RCECS), also by the Institute of Chemical Processes (ICP) in Seoul National University.

Seoul National University assisted in meeting the publication costs of this article.

\section{References}

1. V. M. Dubin, Microelectron. Eng., 70, 461 (2003)

2. P. C. Andricacos, C. Uzoh, J. O. Dukovic, J. Horkans, and H. Deligianni, IBM J. Res. Dev., 42, 567 (1998).

3. S. H. Cha, S.-S. Kim, S. K. Cho, and J. J. Kim, Electrochem. Solid-State Lett., 8, C170 (2005).

4. C. H. Seah, S. Mridha, and L. H. Chan, J. Mater. Process. Technol., 114, 233 (2001).

5. W.-C. Tsai, C.-C. Wan, and Y.-Y. Wang, J. Electrochem. Soc., 150, C267 (2003)

6. S.-C. Chang, J.-M. Shieh, B.-T. Dai, and M.-S. Feng, J. Vac. Sci. Technol. B, 20, 2295 (2002).

7. A. C. West, H. Deligianni, and P. C. Andricacos, IBM J. Res. Dev., 49, 37 (2005). 